\title{
Treatment of Hepatitis C Virus and Long-Term Effect on Glycemic Control
}

\author{
Jennifer Andres, PharmD, BCPS; Michael Barros, PharmD, BCPS, BC-ADM;
} Michael Arutunian, PharmD; and Huaqing Zhao, PhD

\begin{abstract}
BACKGROUND: Chronic hepatitis C virus (HCV) infection has been linked to worsening glycemic control in patients with diabetes due to insulin resistance. Studies have shown that treating HCV improves glycemic control in this patient population. Most studies assess glycemic control until the patient's sustained viral response at 12 weeks (SVR12).
\end{abstract}

OBJECTIVES: To (a) assess the sustainability of glycemic control after the SVR12 date and (b) determine the change in diabetic medication use over time.

METHODS: This was a retrospective chart review of patients treated at an academic medical center's hepatology clinic from 2014 through 2017. Patients were eligible for review if they were treated for hepatitis $C$ and had type 2 diabetes mellitus (DM) or pre-DM, defined by a hemoglobin A1c (A1C) $>5.7 \%$, at baseline. Data were collected from the EPIC database available to Temple University Hospital. Results were analyzed using a linear mixed model and descriptive statistics.

RESULTS: Of the 1,073 patients screened, 310 met the eligibility criteria. Most patients achieved SVR12 (87.8\%). A statistically significant decrease in A1c from baseline to treatment completion with direct-acting antivirals (DAAs) and until current reading was seen $(P<0.05)$. Overall, A1c was reduced in patients treated for HCV with DAA by $-0.27 \%(95 \%$ $\mathrm{Cl}=-0.479 \%$ to $-0.055 \%, P=0.014)$ from baseline to current reading. No statistically significant difference existed in A1c at time of SVR12 to current reading (difference in $\mathrm{A} 1 \mathrm{C}=0.07 \%, 95 \% \mathrm{Cl}=-0.26 \%$ to $0.4 \%, P=0.67$ ), indicating that the reduction in A1c achieved by treating HCV can be sustained over time. Insulin dose also decreased from baseline to current values.

CONCLUSIONS: Overall, patients with diabetes successfully treated for the hepatitis $C$ virus may be able to maintain improved glycemic control past SVR12. This could lead to less antidiabetic medication use and decreased insulin requirements for this patient population.

J Manag Care Spec Pharm. 2020;26(6):775-81

Copyright @ 2020, Academy of Managed Care Pharmacy. All rights reserved.

\section{What is already known about this subject}

Patients with diabetes or prediabetes treated for chronic hepatitis $C$ virus with direct-acting antivirals have shown improvements in glycemic control at the time of sustained virologic response at 12 weeks (SVR12) and soon thereafter.

Few studies have assessed glycemic control past the SVR12 date.

\section{What this study adds}

Patients with diabetes or prediabetes at our institution had improvements at SVR12 in glycemic control.

Glycemic control showed improvements for up to 3 years following SVR12 in some patients.

Overall, the use of insulin and other antidiabetic medications decreased during the study period.

T he hepatitis $\mathrm{C}$ virus (HCV) is considered the most common blood-borne pathogen, with more than 3 million people chronically infected with the disease in the United States. ${ }^{1}$ Chronic HCV infection is about 5 times more common than human immunodeficiency virus (HIV) and is accountable for approximately 10,000 chronic liver diseaseassociated deaths a year. ${ }^{1} \mathrm{HCV}$ is not directly cytopathic to hepatocytes. Instead, hepatic injury is associated with the innate and adaptive immune responses of the host that causes cellular necrosis. The resulting tissue damage plays a role in the extrahepatic manifestations of chronic HCV. ${ }^{2}$ Extrahepatic manifestations can lead to renal damage, cardiovascular diseases, arthralgias, vasculitis, arthritis, neuropathies, and insulin resistance (IR). ${ }^{1-3}$

Insulin is an essential hormone in postprandial storage of nutrients derived from food intake and is secreted in response to elevations in blood glucose. When insulin acts on the liver, it promotes the production of adenosine triphosphate and replenishment of glycogen stores for the body to use in fasted states. ${ }^{4}$ Multiple signaling pathways are involved in insulin effects, but the insulin receptor substrate -1 and -2 (IRS-1 and IRS-2) proteins found in hepatocytes, play important roles in regulation of gluconeogenesis and lipid metabolism. ${ }^{3-5}$

Multiple factors contribute to the development of IR in patients with $\mathrm{HCV}$, including steatosis, metabolic syndrome, and chronic inflammatory processes. ${ }^{4}$ Steatosis, a disease frequently observed in $\mathrm{HCV}$, has been associated with IR. A decreased rate of required glucose is associated with higher levels of insulin in patients with steatosis when compared with the control group without steatosis. ${ }^{6}$ Fasting insulin levels were about 2 times greater in 46 patients with nonalcoholic fatty liver disease (NAFLD) than the 92 patients in the control group (103 pmol/L vs. $60 \mathrm{pmol} / \mathrm{L}$, respectively), whereas the 
difference in fasting blood glucose was minimal. Insulin resistance according to the homeostasis model assessment (HOMA-IR) was also found to be significantly different between the NAFLD group and the control (3.3\% vs. 1.8\%, $P<0.001){ }^{7}$ These studies suggest liver fat plays an important role in the development of IR. Patients with features of the metabolic syndrome such as hypertension and dyslipidemia are already at risk for developing cardiovascular disease and type 2 diabetes mellitus (DM)., ${ }^{4,8}$ The chronic inflammatory state of the liver in HCV causes increased production of cytokines that can increase IR. ${ }^{4}$ The proinflammatory cytokines such as tumor necrosis factor-alpha and interleukin-6 (IL-6) can either inhibit insulin action or induce IR by mediating the degradation of the IRS-1 and IRS-2 proteins, which ultimately results in reduced insulin signaling. ${ }^{3,4}$

Studies have associated the prevalence and development of type $2 \mathrm{DM}$ in patients with chronic HCV infection..$^{5,9}$ Mehta et al. (2000) evaluated 9,841 persons from the third National Health and Nutrition Examination Survey and found after adjustment of certain factors (age, race, body mass index, and socioeconomic status), people aged 40 years or older with $\mathrm{HCV}$ infection were more than 3 times more likely to have type $2 \mathrm{DM}$ than those without HCV infection (adjusted odds ratio $[\mathrm{OR}]=3.77,95 \%$ confidence interval $[\mathrm{CI}]=1.80-7.87) .{ }^{10} \mathrm{~A}$ cross-sectional survey of more than 9,000 patients in Taiwan showed a higher prevalence of $\mathrm{HCV}$ in patients with type 2 DM when compared with their non-type 2 DM group (6.9\% vs. $4.5 \%, P<0.001){ }^{11}$

Although these studies show the correlation between chronic HCV infection and diabetes, other studies have sought to observe the changes in glycemic control and insulin resistance in patients treated for chronic HCV. ${ }^{12-17}$ Kawaguchi et al. (2007) analyzed the HOMA-IR patients with chronic HCV receiving interferon with or without ribavirin. Patients who did not respond to therapy or relapsed did not have any significant changes in their HOMA-IR, whereas responders did experience a significant decrease in HOMA-IR values $(1.7 \pm 0.8$ from $3.1 \pm 1.1 ; P<0.05) .{ }^{12}$ The Hepatitis $C$ Antiviral Long-Term Treatment against Cirrhosis (HALT-C) Trial sought to evaluate if successful suppression of HCV with interferon and ribavirin was associated with improved HOMA-IR. The mean differences in HOMA-IR values were $-2.23,0.90$, and +0.18 for complete responders, partial responders, and nonresponders, respectively $(P=0.036){ }^{13}$

Other studies observed the differences in hemoglobin Alc (Alc) at baseline and sustained viral response at 12 weeks (SVR12) after patients completed their course of direct-acting antivirals (DAAs). An overall decrease in Alc was observed in patients with elevated baseline Alc who achieve SVR versus those who sustained treatment failure. ${ }^{14-17}$ Hum et al. (2017) observed an overall decrease of $0.98 \%$ in Alc in the 2,180 patients who have achieved SVR compared with the
255 patients who failed treatment $(0.65 \%$ decrease, adjusted mean difference $=0.34, P=0.02$ ). A reduction in insulin use up to 15 months posttreatment was seen (from $42 \%$ to $38 \%$ ) in patients who achieved SVR. Insulin use increased from 50\% to $51 \%$ in patients who failed treatment. Patients were followed for up to 1 year after completing DAAs. ${ }^{14}$ Dawood et al. (2017) reported that among patients who achieved SVR12, 77.2\% achieved improvement in glycemic control, as evidenced by the mean decrease in Alc by $0.8 \%$ and a reduction of $49.1 \mathrm{mg} /$ $\mathrm{dL}$ in their fasting plasma glucose levels. More than $25 \%$ of the patients achieving improved glycemic control also experienced a decrease in their antidiabetic regimens, with a majority of these patients requiring a decrease in their insulin dosage..$^{15}$ Additionally, Ciancio et al. (2018) observed a mean decrease in Alc of $0.5 \%$ in patients achieving SVR12, and Abdel Alem et al. (2017) observed a similar decrease in their patients 24 weeks after treatment. ${ }^{16,17}$ These studies discuss the positive effect DAAs have on glycemic control for up to 1 year after SVR12. Because patients will have diabetes past this date, it is important to understand how achievement of SVR12 long term affects glycemic control.

The objective of this study was to assess if glycemic improvement is sustainable after the SVR12 date until the last current reading. It is also important to understand how glycemic control affects patients with impaired glucose function and prediabetes and if this differs from patients with established diabetes

\section{Methods}

This was a retrospective, observational chart review of patients referred to the hepatology clinic at our tertiary care, urban, academic medical center and treated for HCV infection with DAAs with type 2 DM or pre-DM from January 1, 2014, to December 31, 2017. Type 2 DM or pre-DM was defined by the patient problem list in EPIC or an Alc of $\geq 5.7 \%$. Patients could be included if they had an Alc $<5.7 \%$ if they were on medications for DM to ensure well-controlled patients with diabetes or prediabetes were included. Patients were excluded if they received an HCV regimen containing interferon.

Data were collected from the EPIC database at our institution from January 2018 through August 2018. HCV treatment demographics collected included treatment history, genotype, DAA regimen, and baseline viral load. Achievement of SVR12 was also documented.

Data collected to assess diabetes included Alc at up to 5 intervals (within 1 year before DAA therapy or baseline, during DAA therapy, after DAA therapy but before SVR12, at SVR12 date or 1 month after, 1 year after completion of DAA therapy, and the most current value). Antidiabetic medications (both insulin and noninsulin) were assessed at the same intervals. Total daily dose of insulin was reviewed for each patient. In patients on sliding-scale insulin, the average of the high and 


\section{TABLE 1 Baseline Characteristics of Study Population}

Male, \% (n)

Mean age, years, (SD [range])

Race/ethnicity, \% (n)

\begin{tabular}{|c|c|c|}
\hline White & 8.12 & (25) \\
\hline African American/Black & 63.64 & (196) \\
\hline Hispanic or Latino & 27.2 & (84) \\
\hline Other & 0.97 & (3) \\
\hline Unknown/not reported & 0.65 & (2) \\
\hline \multicolumn{3}{|c|}{ Family history of DM, \% (n) } \\
\hline Mother & 27.5 & (86) \\
\hline Father & 13.5 & $(42)$ \\
\hline Siblings & 19.6 & $(61)$ \\
\hline No family history & 50.9 & (159) \\
\hline \multicolumn{3}{|c|}{ Hepatitis C treatment history, \% (n) } \\
\hline Treatment naive & 79.3 & $(246)$ \\
\hline Treatment experienced & 20.7 & $(64)$ \\
\hline
\end{tabular}

\section{Genotype, $n$}

\begin{tabular}{l|c}
\hline la & 204 \\
\hline $1 \mathrm{~b}$ & 74 \\
\hline 2 & 18 \\
\hline 3 & 13 \\
\hline 4 & 9 \\
\hline 6 & 1 \\
\hline
\end{tabular}

Baseline Alc ( $\mathrm{n}=266), \%(\mathrm{n})$

\begin{tabular}{|c|c|c|}
\hline$\geq 10.0 \%$ & 5.9 & (16) \\
\hline $9.0 \%-9.9 \%$ & 7.4 & $(20)$ \\
\hline $8.0 \%-8.9 \%$ & 4.8 & (13) \\
\hline $7.0 \%-7.9 \%$ & 17.3 & $(47)$ \\
\hline $6.5 \%-6.9 \%$ & 12.9 & (35) \\
\hline $5.7 \%-6.4 \%$ & 47.2 & $(128)$ \\
\hline$<5.7 \%$ & 4.4 & (12) \\
\hline \multicolumn{3}{|l|}{ Weight, kg (SD [range]) } \\
\hline Baseline weight $(\mathrm{n}=304)$ & 90.6 & $(23.2[43-215])$ \\
\hline Weight during DAA treatment $(\mathrm{n}=248)$ & 91.3 & $(23.6[45-219])$ \\
\hline SVRl2 weight $(\mathrm{n}=186)$ & 88.6 & $(20.0[44-153])$ \\
\hline \multicolumn{3}{|l|}{ Alpha fetoprotein, ng/mL (SD [range]) } \\
\hline Baseline $(n=256)$ & \multicolumn{2}{|c|}{$74.1(989.78[0.8-15,844])$} \\
\hline Current $(n=68)$ & 6.43 & $(5.85[1.1-36.3])$ \\
\hline \multicolumn{3}{|c|}{ International normalized ratio (SD [range]) } \\
\hline Baseline $(n=296)$ & 1.06 & $(0.15[0.8-2.9])$ \\
\hline Current $(n=107)$ & 1.11 & $(0.31[0.9-3.5])$ \\
\hline \multicolumn{3}{|l|}{ Albumin, g/dL (SD [range]) } \\
\hline Baseline $(\mathrm{n}=301)$ & 3.89 & $(0.53[1.4-4.9])$ \\
\hline Current $(n=187)$ & 4.02 & $(0.87$ [1.1-12.9]) \\
\hline
\end{tabular}

\begin{tabular}{|c|c|c|}
\hline \multicolumn{3}{|l|}{ Total bilirubin, mg/dL (SD [range]) } \\
\hline Baseline $(n=302)$ & 0.67 & $(0.52[0.1-5.9])$ \\
\hline \multicolumn{3}{|l|}{ Hemoglobin, g/dL (SD [range]) } \\
\hline Baseline $(n=308)$ & 13.51 & $(1.65[7.3-17.4])$ \\
\hline Current $(n=196)$ & 13.19 & $(1.74[7.5-17.2])$ \\
\hline \multicolumn{3}{|l|}{ Platelets, 103uL (SD [range]) } \\
\hline Baseline $(n=306)$ & 192.9 & $(69.2[1.2-439])$ \\
\hline Current $(n=196)$ & 200.5 & $(69.7[46-484])$ \\
\hline \multicolumn{3}{|l|}{ Serum creatinine, $\mathrm{mg} / \mathrm{dL}$ (SD[range]) } \\
\hline Baseline $(\mathrm{n}=303)$ & 1.08 & $(0.61[0.51-5.83])$ \\
\hline Current $(\mathrm{n}=193)$ & 1.22 & $(0.87[0.56-7.51])$ \\
\hline \multicolumn{3}{|l|}{ Diabetes regimen at baseline, $\%(n)$} \\
\hline Monotherapy & 19.6 & $(61)$ \\
\hline Dual therapy & 20.6 & (64) \\
\hline Triple therapy & 8.7 & $(27)$ \\
\hline$>3$ antidiabetic medications & 3.8 & (12) \\
\hline No therapy & 47.3 & $(147)$ \\
\hline \multicolumn{3}{|l|}{ Diabetes classes used at baseline, $n$} \\
\hline Biguanides & & 100 \\
\hline Sulfonylureas & & 54 \\
\hline DPP-4 & & 13 \\
\hline SGLT2 & & 0 \\
\hline Alpha-glucosidase inhibitors & & 0 \\
\hline TZD & & 2 \\
\hline GLP-1 RA & & 7 \\
\hline Insulin & & 93 \\
\hline \multicolumn{3}{|l|}{ DAA regimen, \% (n) } \\
\hline Sofosbuvir/ledipasvir & 68.5 & $(213)$ \\
\hline +ribavirin & 9.0 & $(28)$ \\
\hline Sofosbuvir/velpatasvir & 3.5 & (11) \\
\hline +ribavirin & 1.0 & (3) \\
\hline Sofosbuvir/simeprevir & 5.8 & (18) \\
\hline + ribavirin & 1.0 & (3) \\
\hline Sofosbuvir/daclatasvir & 2.9 & (9) \\
\hline + ribavirin & 0.6 & (2) \\
\hline Elbasvir/grazoprevir & 11.9 & $(37)$ \\
\hline +ribavirin & 1.3 & $(4)$ \\
\hline Ombitasvir/paritaprevir/ritonavir/dasabuvir & 4.2 & $(13)$ \\
\hline +ribavirin & 2.6 & $(8)$ \\
\hline Sofosbuvir+ribavirin & 4.2 & $(13)$ \\
\hline \multicolumn{3}{|l|}{ SVR12 achieved, \% (n) } \\
\hline Yes & 87.4 & $(271)$ \\
\hline No & 2.9 & (9) \\
\hline Unknown/not reported & 9.7 & (30) \\
\hline
\end{tabular}

aSome patients fit into multiple ethnic/racial groups.

Alc =hemoglobin Alc; DAA = direct-acting antiviral; DM=diabetes mellitus; DPP-4=dipeptidyl peptidase-4; GLP-1 RA=glucagon-like peptide 1 receptor agonist;

$S D=$ standard deviation; $S G L T 2=$ sodium glucose co-transporter $2 ; S V R 12=$ sustained virologic response at 12 weeks; TZD=thiazolidinedione.

low insulin units was used in data analysis. Data were also collected on clinical findings that can affect glycemic control, such as patient weight, sickle cell disease or trait, hepatocellular carcinoma diagnosis at any time, anemia before and following therapy at SVR12 (if available) as defined by a hemoglobin of $<13 \%$ for males and $<12 \%$ for females, among others.
A linear mixed-effects model was used to compare Alc from baseline to after baseline (during DAA therapy, after DAA therapy but before SVR12, at SVR12 date or 1 month after, 1 year after completion of DAA therapy, and the most current value). The effect of various factors on the Alc reduction from baseline values to after baseline values was also assessed 


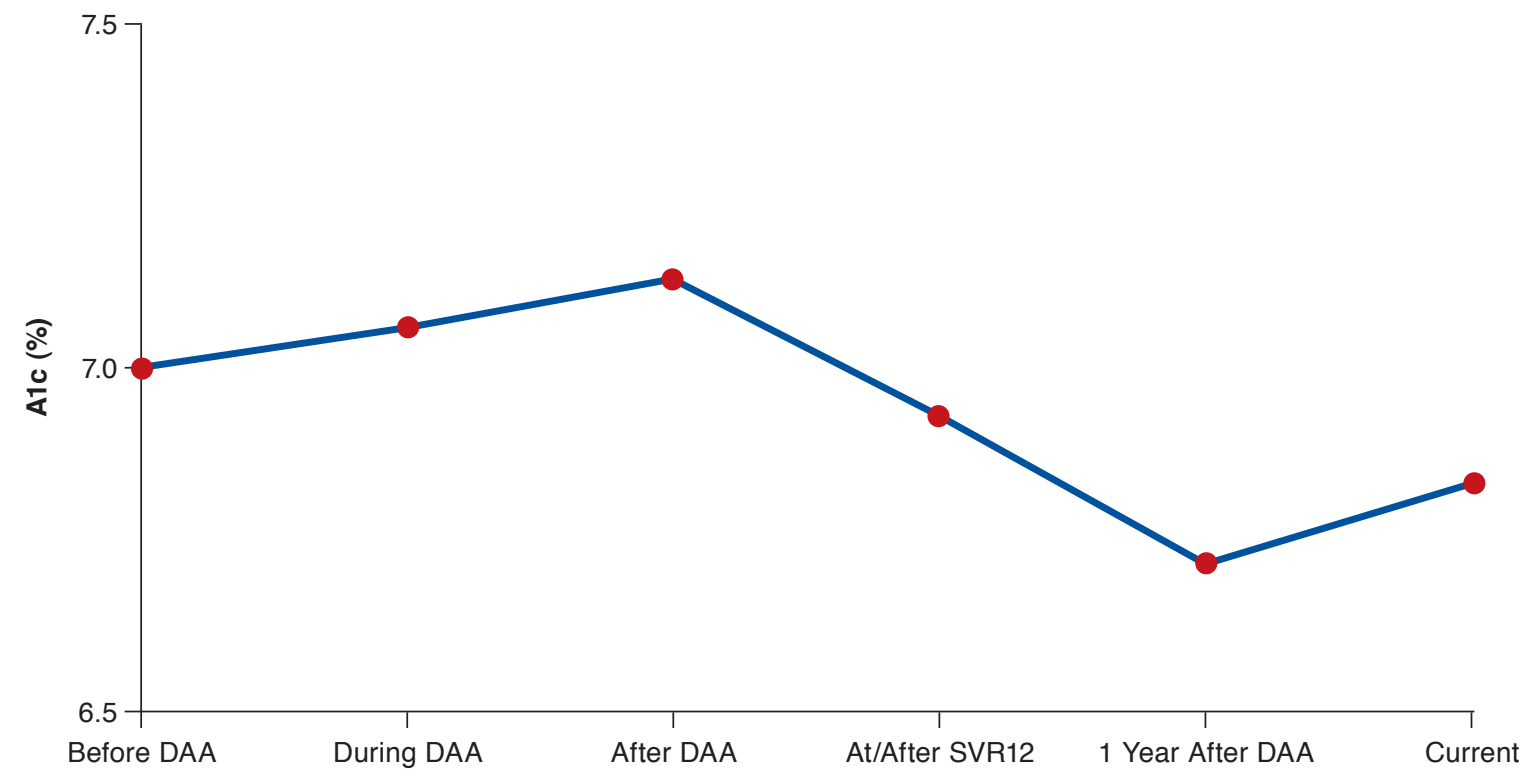

$A 1 c=$ hemoglobin $A 1 c ; D A A=$ direct-acting antiviral; $S V R=$ sustained viral response.

to determine effect on findings. All statistical analyses were performed using SAS software package 9.4 (SAS Institute, Cary, NC) and Stata software package 14.0 (StataCorp, College Station, TX). A significant difference was defined as $P<0.05$. This study was approved by our institution's institutional review board.

\section{Results}

Of the 1,073 patient charts screened for this review, 310 met the eligibility criteria. Of the 310 patients, 266 patients had baseline Alc data that met the inclusion criteria; the remaining 44 patients did not have Alc data within defined parameters, but still met eligibility criteria of type $2 \mathrm{DM}$ or pre-DM being listed in their active problem list. Full baseline characteristics can be found in Table 1. Patients were mostly African American and male, with a mean age of 61.8 years. A majority of the patients had never been treated for HCV infection, and most were found to have genotype la. Most patients achieved SVR12 (87.4\%); however, a small number failed to achieve SVR12 (2.9\%), and 30 patients were lost to follow up (9.7\%).

Of the 266 patients with baseline data, 128 had baseline Alc values of 5.7\%-6.4\%. Twelve patients with diabetes per problem list had baseline Alc below 5.7\%. Most patients with prediabetes were not receiving pharmacotherapy $(n=147)$, but 25 patients with an Alc of $\leq 6.4 \%$ were receiving pharmacotherapy. Eighty-six patients with an $\mathrm{Alc} \geq 6.5 \%$ were receiving pharmacotherapy.
In patients receiving pharmacotherapy, a similar number of patients received either monotherapy or dual therapy (61 and 64 , respectively). Ninety-three of the 310 patients (30.0\%) were taking insulin as part of their diabetes regimen. Baseline use of different classes of antidiabetic medications including insulin is, on average, higher in the groups with higher baseline Alc. The pre-DM groups had a significantly lower amount of antidiabetic agent use when compared with the other cohorts.

swIn patients with baseline Alc values, the median time of follow-up is 1.6 year (interquartile range $=0.9$ to 3.1 years). Figure 1 describes the Alc in each subgroup of patients. Overall, a statistically significant decrease in Alc was seen from baseline to DAA treatment completion and until current reading $(P<0.05)$. Patients also had a reduction in Alc from baseline to SVR12 date with a reduction of $-0.34(95 \% \mathrm{CI}=-0.66$ to $-0.02 ; P=0.037)$. One hundred and sixty-seven patients had baseline and current Alc values that could be compared. The average duration between these values was 798 days (range 147-1,644 days). Overall, Alc was reduced in patients treated for $\mathrm{HCV}$ with DAAs by $-0.27 \%$ (95\% CI $=-0.479 \%$ to $-0.055 \%$, $P=0.014)$ from baseline to current reading. No statistically significant difference existed in Alc at time of SVR12 to current reading $(0.07 \%, 95 \% \mathrm{CI}=-0.26 \%$ to $0.4 \%, P=0.67)$, indicating that the reduction in Alc achieved by treating HCV can be sustained over time. Similar Alc changes were seen after adjusted for age, gender, race, ethnicity, presence of cirrhosis, fibrosis stage, and SVR12 achievement. Table 2 describes the Alc changes in each subgroup of patients during the study period. 


\begin{tabular}{|c|c|c|c|}
\hline Comparison & \begin{tabular}{|c|} 
Difference in \\
Alc (\%)
\end{tabular} & $\begin{array}{l}\text { 95\% Confidence } \\
\text { Interval }\end{array}$ & $P$ Value \\
\hline During DAA vs. baseline & -0.12 & -0.423 to 0.173 & 0.41 \\
\hline After DAA vs. baseline & -0.41 & -0.735 to -0.09 & $0.012^{\mathrm{a}}$ \\
\hline At/after SVR12 vs. baseline & -0.34 & -0.658 to -0.02 & $0.037^{a}$ \\
\hline 1 year after DAA vs. baseline & -0.4 & -0.717 to -0.086 & $0.013^{a}$ \\
\hline Current ${ }^{\mathrm{b}}$ vs. baseline & -0.27 & -0.479 to -0.055 & $0.014^{a}$ \\
\hline Current vs. at/after SVR12 & 0.07 & -0.261 to 0.404 & 0.67 \\
\hline Current vs. 1 year after DAA & 0.13 & -0.192 to 0.461 & 0.42 \\
\hline \multicolumn{4}{|c|}{$\begin{array}{l}\text { aP<0.05. } \\
\text { bDefined as } 1.5 \text { months-3 years past SVR } 12 . \\
\text { Alc=hemoglobin Alc; DAA=direct-acting antiviral; SVR } 12=\text { sustained virologic } \\
\text { response at } 12 \text { weeks. }\end{array}$} \\
\hline
\end{tabular}

Alc significantly decreased from baseline to current values in patients who received DAA treatment.

No significant association was seen in the dose of insulin and number of oral antidiabetic medications on Alc change. In patients taking insulin, an overall decrease in total daily insulin use was observed in most cohorts that achieved SVR12, with the most significant decreases being observed in the 6.5\%-6.9\% and in patients with Alc $\leq 6.5 \%$ (average decrease of 10.8 and 9.6 units, respectively) as shown in Table 3. An increase of 10.5 units in total daily insulin use was observed in the patients with baseline Alc in 8.0\%-8.9\% range. There was no change in insulin use in the 1 patient who did not achieve SVR12. Overall, there was a trend towards fewer classes of oral antidiabetic agents used from baseline to current use, as shown in Table 4. Any differences in the use of different antidiabetic agents from baseline to the current agents were largely insignificant, especially in the patients who achieved SVR12.

\section{Discussion}

This evaluation is the first, to our knowledge, to show that treating patients for hepatitis $C$ infection leads to improved glycemic control up to 3 years after treatment. This finding remained after controlling for baseline characteristics such as race, age, ethnicity, gender, presence of cirrhosis, fibrosis stage, and SVR12 achievement.

Although the authors expected more of a difference in the use of antidiabetic agents from baseline to current findings, there were minimal changes. Data indicated that patients tended to be on less antidiabetic medication at current time; however, this result was not statistically significant. Our results are similar to the Hum study, which found the number of medications from baseline to post-SVR did not change. ${ }^{9}$ Patients had lower Alc values despite being on similar amounts of medications from baseline. This indicates that use of antidiabetic medication did not drive the reduction in Alc. Given the progressive nature of diabetes, leading to increased use

\begin{tabular}{|c|c|c|c|}
\hline \multirow[b]{2}{*}{$\begin{array}{l}\text { Baseline } \\
\text { Alc, \% (n) }\end{array}$} & \multicolumn{3}{|c|}{ SVR12 Achieved } \\
\hline & $\begin{array}{c}\text { Yes, units } \\
(\text { SD [range] }) \mathrm{n}=55\end{array}$ & $\begin{array}{c}\text { No, units } \\
(\mathrm{SD}[\text { range] }) \mathrm{n}=\mathbf{2}\end{array}$ & $\begin{array}{l}\text { Unknown, units } \\
(\text { SD [range]) } n=4\end{array}$ \\
\hline$\geq 10.0$ & $\begin{array}{c}8.3 \\
(43.8[-25 \text { to } 96]) \\
\end{array}$ & $\begin{array}{c}50.0 \\
(70.7[0 \text { to } 100]) \\
\end{array}$ & -38.0 \\
\hline 9.0-9.9 (15) & $\begin{array}{c}-17.8 \\
(42.1[-141 \text { to } 34])\end{array}$ & N/A & N/A \\
\hline $8.0-8.9 \quad(6)$ & $\begin{array}{c}10.5 \\
(44.2[-25 \text { to } 75])\end{array}$ & N/A & $\begin{array}{l}-11.5 \text { units } \\
(2.1[-13 \text { to }-10])\end{array}$ \\
\hline 7.0-7.9 (19) & $\begin{array}{c}-2.3 \\
(21.9[-40 \text { to } 40])\end{array}$ & N/A & N/A \\
\hline 6.5-6.9 (8) & $\begin{array}{c}-10.8 \\
(20.5[-52 \text { to } 0])\end{array}$ & N/A & N/A \\
\hline $5.9-6.4 \quad(4)$ & $\begin{array}{c}-9.6 \\
(29.1[-51 \text { to } 30])\end{array}$ & N/A & N/A \\
\hline
\end{tabular}

a Defined as 1.5 months-3 years past SVR12.

Alc = hemoglobin Alc; N/A = not applicable; $S D=$ standard deviation; SVR12 = sustained virologic response at 12 weeks.

of antidiabetic medication over time, the authors believe this finding is clinically relevant in showing that achieving SVR12 with DAAs may slow the progression of diabetes and allow continuation of current diabetes regimens without further need for treatment intensification. This could have implications for cost and patient adherence. Dose of noninsulin agents was not captured, so it is unknown if intensity of treatment dose was changed. Overall, most patients had a reduction in total daily insulin dose from baseline to current time, which may have cost benefits for patients.

According to results, patients with higher baseline Alc not only have a larger decrease in Alc, but Alc reduction may be sustainable up to at least 3 years post-HCV therapy. The sustainability of a reduced Alc and improved glycemic control may prevent microvascular complications often associated with diabetes, namely nephropathy, peripheral neuropathy, and retinopathy; however, these complications were not tracked in this analysis.

\section{Strengths and Limitations}

A main strength of this study was the evaluation of Alc in patients over an extended timeframe. Although some studies followed patients to SVR12 or SVR24,,$^{11,12}$ this study followed patients for up to 3 years after SVR12 to observe the sustainability of improved glycemic control. Patients were stratified based on baseline Alc, separating patients with prediabetes, controlled diabetes, and those with poorly controlled diabetes, accounting for the possibility of different outcomes based on initial glycemic control. Another strength of our study included our patient population, which consisted of a large number of African Americans and patients of Hispanic/Latino ethnicity. These patients are usually underrepresented in most studies, 


\section{REFERENCES}

1. Deming P. Viral hepatitis. In: DiPiro JT, Talbert RL, Yee GC, et al., eds. Pharmacotherapy, A Pathophysiologic Approach. 10th ed. Norwalk, CT: Appleton \& Lange; 2017:561-78.

2. Dienstag JL. Acute viral hepatitis. In: Kasper D, Fauci A, Hauser S, Longo D, Jameson JL, Loscalzo J, eds. Harrison's Internal Medicine. 19th ed. New York: McGraw-Hill; 2015:2004-22.

3. Cacoub P, Gragnani L, Comarmond C, Zignego AL. Extrahepatic manifestations of chronic hepatitis C virus infection. Dig Liver Dis. 2014;46 (Suppl 5):S165-73.

4. Serfaty L, Capeau J. Hepatitis C, insulin resistance and diabetes: clinical and pathogenic data. Liver Int. 2009;29(Suppl 2):13-25.

5. Sherman AC, Sherman KE. Extrahepatic manifestations of hepatitis $C$ infection: navigating CHASM. Curr HIVIAIDS Rep. 2015;12(3):353-61.

6. Sanyal AJ, Campbell-Sargent C, Mirshahi F, et al. Nonalcoholic steatohepatitis: association of insulin resistance and mitochondrial abnormalities. Gastroenterology. 2001;120(5):1183-92.

7. Marchesini G, Brizi M, Morselli-Labate AM, et al. Association of nonalcoholic fatty liver disease with insulin resistance. Am J Med. 1999;107(5):450-55.

8. Kotronen A, Westerbacka J, Bergholm R, et al. Liver fat in the metabolic syndrome. J Clin Endocrinol Metab. 2007;92(9):3490-97.

9. Desbois AC, Cacoub C. Diabetes mellitus, insulin resistance and hepatitis C virus infection: a contemporary review. World J Gastroenterol. 2017;23(9):1697-711.

10. Mehta SH, Brancati F, Sulkowski MS, et al. Prevalence of type 2 diabetes mellitus among persons with hepatitis $C$ virus infection in the United States. Ann Intern Med. 2000;133(8):592-99.
11. Huang JF, Dai CY, Hwang SJ, et al. Hepatitis C viremia increases the association with type 2 diabetes mellitus in a hepatitis B and C endemic area: an epidemiological link with virological implication. Am J Gastroenterol. 2007;102(6):1237-43

12. Kawaguchi T, Ide T, Taniguchi E, et al. Clearance of HCV improves insulin resistance, beta-cell function, and hepatic expression of insulin receptor substrate 1 and 2. Am J Gastroenterol. 2007;102(3):570-76.

13. Delgado-Borrego A, Jordan SH, Negre B, et al. Reduction of insulin resistance with effective clearance of hepatitis $C$ infection: results from the HALT-C trial. Clin Gastroenterol Hepatol. 2010;8(5):458-62.

14. Hum J, Jou JH, Green PK, et al. Improvement in glycemic control of type 2 diabetes after successful treatment of hepatitis $C$ virus. Diabetes Care. 2017:40(9):1173-80

15. Dawood AA, Nooh MZ, Elgamal AA. Factors associated with improved glycemic control by direct-acting antiviral agent treatment in Egyptian type 2 diabetes mellitus patients with chronic hepatitis $C$ genotype 4 . Diabetes Metab J. 2017;41(4):316-21.

16. Ciancio A, Bosio R, Simona B, et al. Significant improvement of glycemic control in diabetic patients with HCV infection responding to direct-acting antiviral agents. J Med Virol. 2018;90(2):320-27.

17. Abdel Alem S, Elsharkawy A, Fouad R, et al. Improvement of glycemic state among responders to sofosbuvir-based treatment regimens: single center experience. J Med Virol. 2017;89(12):2181-87.

18. Ziemer DC, El-Kebbi IM, Umpierrez GE, et al. Diabetes management in urban African Americans: review of a public health experience. Ethn Dis. 2008;18(3):336-41.

19. Marshall MC. Diabetes in African Americans. Postgrad Med J. 2005;81(962):734-40 